Published in final edited form as:

Eur Urol Rev. 2011 ; 6(2): 90-96.

\title{
Management of metastatic castration-resistant prostate cancer
}

\author{
Emmanuel S. Antonarakis, M.D. \\ Sidney Kimmel Comprehensive Cancer Center at Johns Hopkins, Baltimore, MD, USA
}

\begin{abstract}
The management of men with metastatic castration-resistant prostate cancer (CRPC) has taken several leaps forward in the last 2 years, with the demonstration of improved overall survival with three novel agents (sipuleucel-T, cabazitaxel, and abiraterone acetate), and a significant delay in skeletal-related events observed with denosumab. The pipeline of systemic therapies in prostate cancer remains strong, as multiple agents with a diverse array of mechanisms of action are demonstrating preliminary signs of clinical benefit, leading to more definitive phase III confirmatory trials. In this review, we will discuss the evolving landscape of treatment options for men with CRPC, with a particular focus on currently approved and emerging treatment options for these patients. Knowledge of these evolving standards will help to optimize delivery of care and long term outcomes in men with advanced CRPC.
\end{abstract}

\section{Keywords}

castration-resistant prostate cancer; novel therapies; drug development; sipuleucel-T; cabazitaxel; abiraterone; denosumab; orteronel; MDV3100; ipilimumab

\section{INTRODUCTION}

While much of the recent focus on prostate cancer relates to the over-diagnosis and overtreatment of this disease, each year almost 100,000 men in Europe and more than 30,000 men in the United States still die of advanced prostate cancer, making it the second most common cause of cancer-related deaths. ${ }^{1}$ Androgen deprivation therapy is the most effective systemic treatment for recurrent prostate cancer; however, the vast majority of these patients will eventually develop resistance to hormonal approaches (Table 1) necessitating other forms of therapy. Although several chemotherapeutic strategies have been employed to treat castration-resistant prostate cancer (CRPC), it was not until 2004 that one such approach was shown to be life-prolonging. In that year, two phase III clinical trials reported a survival advantage with the use of docetaxel chemotherapy in men with metastatic CRPC, ${ }^{2,3}$ resulting in the US FDA-approval of this agent. However, while docetaxel is both palliative and life-prolonging, it is not the ultimate answer for patients with CRPC, as virtually all men develop eventual resistance to this chemotherapy agent or are unable to tolerate its toxicities long term.

Until 2010, there were no additional treatment options conferring a survival benefit for patients with CRPC, although mitoxantrone was often employed in these patients for its palliative effects on bone pain. ${ }^{4}$ This situation changed in 2010 when an autologous

Correspondence: E. S. Antonarakis, Prostate Cancer Research Program, Sidney Kimmel Comprehensive Cancer Center at Johns Hopkins, 1650 Orleans Street, CRB1-1M45, Baltimore, MD 21231-1000, USA; phone: 443-287-0553, fax: 410-614-8397, eantona1@jhmi.edu.

Conflict of Interest: Dr Antonarakis has served as an advisor/consultant for Sanofi-Aventis. 
immunotherapy product, sipuleucel-T, was FDA-approved for the treatment of minimally symptomatic or asymptomatic metastatic CRPC, based on the results of a randomized phase III trial comparing this agent against placebo. In that same year, a randomized phase III trial demonstrated a survival advantage for a novel taxane, cabazitaxel, over mitoxantrone in men with metastatic CRPC that had progressed after prior docetaxel therapy. Based on those results, cabazitaxel was approved by the FDA for the second-line treatment of metastatic CRPC. Several months later, an oral agent with the ability to suppress extragonadal androgen synthesis, abiraterone, was also reported to improve survival in a phase III study when evaluated against placebo in men with docetaxel-pretreated metastatic CRPC, resulting in the FDA approval of this agent for patients that have previously received docetaxel (Figure 1).

In addition to these life-prolonging therapies, novel bone-targeting approaches are also being developed to address skeletal complications resulting from bone metastases. To this end, an osteoclast-inhibiting agent, denosumab, was FDA-approved in 2010 for the prevention of skeletal-related events in men with castration-resistant bone metastases after showing superiority against the previously approved bisphosphonate zoledronic acid (Figure 1). Given this abundance of new treatment options, a new question emerges: How do we select men for each new therapy, and in what sequence should these agents rationally be given? This review discusses the four novel therapies that have recently become available for the management of patients with CRPC, and will also highlight emerging agents that have shown promising activity and are currently in phase III clinical development (Table 2).

\section{FOUR NEWLY APPROVED AGENTS}

\section{Sipuleucel-T}

Cancer immunotherapy refers to approaches that attempt to treat cancer by activating an immune response against malignant cells while overcoming tumor-induced tolerance, a major resistance mechanism. Prostate cancer may be an ideal target for immunologic attack because it produces several tissue-specific proteins that may serve as tumor antigens: these include prostate-specific antigen (PSA) and prostatic acid phosphatase (PAP). This notion has been applied to the development of sipuleucel-T (Provenge, Dendreon), an autologous PAP-loaded dendritic cell immunotherapy. ${ }^{5}$ During treatment with sipuleucel-T, a patient's own antigen-presenting cells are collected by leukapheresis and co-incubated with a fusion protein containing PAP linked to granulocyte macrophage-colony-stimulating factor (GM$\mathrm{CSF}$ ). After culturing this fusion protein with the antigen-presenting cells, the primed immunotherapy is then reinfused into the patient, activating T cells via MHC class I and class II molecules and resulting in a PAP-specific antitumor attack. ${ }^{6}$

Several early phase clinical trials using this personalized immunotherapy have been conducted which demonstrated the safety of this personalized cellular product, as well as hinted at the potential ability to improve outcomes. Two small randomized phase 2 trials powered to detect a progression-free survival advantage failed in their primary endpoint but did show a survival advantage of 4-5 months over placebo which was significant. ${ }^{7,8}$ Adverse events with sipuleucel-T are generally mild and include fever, chills/sweats, myalgias, and headache. These usually occur during or shortly after infusion of the immunotherapy.

To definitively evaluate the effect of sipuleucel-T on survival, a pivotal multicenter doubleblind placebo-controlled randomized phase III trial (IMPACT) was conducted in men with asymptomatic or minimally symptomatic metastatic CRPC, ${ }^{9}$ leading to the FDA-approval of this agent in April 2010. In this trial, 512 patients were randomized (2:1) to sipuleucel-T or placebo and the study was powered to detect an overall survival advantage. Notably, this study did not enroll men with visceral metastases or those taking narcotics for cancer pain, 
and most patients $(85 \%)$ were chemotherapy-naïve. Impressively, median overall survival was 25.8 months in the sipuleucel-T group versus 21.7 months in the placebo group (hazard ratio $0.78 ; P=0.03$ ), despite $64 \%$ of patients on placebo crossing over to receive salvage sipuleucel-T. In the subset of patients with prior chemotherapy exposure, overall survival trended in favor of sipuleucel-T, but this effect was not statistically significant. Therefore, although this immunotherapy is approved for all patients with asymptomatic or minimally symptomatic CRPC, it will likely have its largest impact in the pre-chemotherapy setting.

Similar to previous studies with sipuleucel-T, the IMPACT study found no difference in progression-free survival or PSA/radiographic response rates between the two treatment arms. Some investigators attribute the discordance between progression-free and overall survival to a possible class effect of immunotherapy agents, relating to their mechanism of action which is distinct from cytotoxic therapies. To this end, a similar phenomenon has been observed in a study using a PSA-directed poxviral-based immunotherapy product (Prostvac-VF) in men with metastatic CRPC. ${ }^{10}$ Problematic endpoints such as progressionfree survival in CRPC (which may be confounded by bone scan flare or delayed-onset effects) may perhaps be better addressed by revised guidelines using outcomes that are tailored to immunologic agents. ${ }^{11}$

\section{Cabazitaxel with prednisone}

Cabazitaxel (Jevtana, sanofi-aventis) is a novel tubulin-binding taxane that differs from docetaxel and paclitaxel due to its poor affinity for P-glycoprotein, the ATP-dependent drug efflux pump. ${ }^{12}$ In preclinical studies using cancer cell lines and mouse xenograft models, cabazitaxel was shown to be active in both docetaxel-sensitive tumors as well as those with primary or acquired docetaxel resistance. ${ }^{13}$

The first hint of cabazitaxel's safety and efficacy in men with prostate cancer came during phase I testing, where cabazitaxel was administered by intravenous infusion every 3 weeks at escalating doses of $10-25 \mathrm{mg} / \mathrm{m}^{2} .{ }^{14}$ In that study, the principal dose-limiting toxicity was neutropenia. Given the lack of cross-resistance to this agent with docetaxel, and early reports of responses in men with CRPC from this phase 1 trial, a phase 3 trial was launched to evaluate efficacy.

The safety and efficacy of cabazitaxel in patients with advanced prostate cancer was definitively evaluated in a pivotal randomized phase III trial (TROPIC) conducted in 146 institutions across 26 countries, and recruited 755 men with metastatic CRPC who had progressed during/after docetaxel-based chemotherapy. ${ }^{15}$ Of these, 377 patients were randomized to receive mitoxantrone $12 \mathrm{mg} / \mathrm{m}^{2}$ intravenously every three weeks (with oral prednisone $10 \mathrm{mg}$ daily), and 378 patients were assigned to receive cabazitaxel $25 \mathrm{mg} / \mathrm{m}^{2}$ intravenously every three weeks (plus prednisone). This study was the basis of the FDA's approval of cabazitaxel with prednisone for the second-line treatment of docetaxelrefractory metastatic CRPC in June 2010.

After a median follow-up of 12.8 months, overall survival in men receiving cabazitaxel was 15.1 months compared to 12.7 months in men receiving mitoxantrone (hazard ratio 0.70 ; $P<0.0001) .{ }^{15}$ Compared to mitoxantrone, cabazitaxel also significantly lengthened progression-free survival (2.8 months vs 1.4 months; $P<0.0001)$, extended time to PSA progression (6.4 months vs 3.1 months; $P=0.001$ ), increased radiographic tumor response rates $(14.4 \%$ vs $4.4 \% ; P=0.0005)$, and increased PSA response rates $(39.2 \%$ vs $17.8 \%$; $P=0.0002$ ). There were no differences between the two treatment arms with respect to pain responses, or time to pain progression. 
In subset analyses, the survival advantage of cabazitaxel persisted regardless of whether patients had measurable disease or pain, or whether progression had occurred while receiving docetaxel or following a treatment holiday. In addition, cabazitaxel's survival benefit was most pronounced for men with ECOG performance status 0-1 (vs 2), and for patients with disease progression within $<3$ months of docetaxel initiation (vs $\geq 3$ months of docetaxel initiation). ${ }^{15}$ The last observation implies that cabazitaxel may be effective even in men with truly docetaxel-refractory disease.

The most common serious adverse events related to cabazitaxel were hematological, including grade $\geq 3$ neutropenia in $82 \%$ of patients (febrile neutropenia in $8 \%$ ). ${ }^{15}$ This degree of myelosuppression begs the question of whether a lower dose of cabazitaxel (e.g. $20 \mathrm{mg}$ / $\mathrm{m}^{2}$ ) may have been more appropriate, and a randomized trial comparing the safety and efficacy of these two doses $\left(25 \mathrm{mg} / \mathrm{m}^{2}\right.$ vs $\left.20 \mathrm{mg} / \mathrm{m}^{2}\right)$ is now being conducted (Table 2). Use of growth factor support should be strongly considered, as reflected in several national guidelines. ${ }^{16}$ Other non-hematological toxicities included grade $\geq 3$ diarrhea (6\%), and grade $\geq 3$ fatigue (5\%). Encouragingly, although peripheral neuropathy (all grades) was observed in $14 \%$ of patients receiving cabazitaxel, only $1 \%$ developed grade 3 neuropathy.

\section{Abiraterone acetate with prednisone}

Ectopic (adrenal, intratumoral, paracrine) androgen production in the setting of gonadal ablative therapies represents an important resistance mechanism in CRPC (Table 1; Figure 2). Abiraterone acetate (Zytiga, Janssen) is an oral, potent, selective, and irreversible inhibitor of the steroidogenic enzyme CYP17, blocking both its 17a-hydroxylase and its C17,20-lyase activity. ${ }^{17}$ As a result, extra-gonadal androgen production is impaired through the inability to convert pregnenolone to dihydroepiandrostenedione and progesterone to androstenedione. In an initial phase I study in men with chemotherapy-naïve CRPC, it was shown that the primary toxicities of abiraterone (hypertension, hypokalemia, and peripheral edema) were related to a syndrome of secondary mineralocorticoid excess due to feedback upregulation of mineralocorticoid synthesis, and were largely reversible after administration of an aldosterone receptor antagonist or a corticosteroid. ${ }^{18}$ For this reason, in several subsequent trials, abiraterone was combined with low-dose prednisone, which may also enhance the efficacy of abiraterone.

The initial efficacy of abiraterone in CRPC was investigated in several phase II trials. In patients with chemotherapy-naïve metastatic CRPC, $250 \%$ PSA declines were seen in approximately $65 \%$ of men, and radiographic tumor responses occurred in about $35 \%$ of men, ${ }^{19}$ with responses noted even among men who had prior ketoconazole exposure. ${ }^{20}$ Finally, in patients with docetaxel-refractory metastatic CRPC, 250\% PSA declines were observed in approximately $40 \%$ of men and objective tumor responses occurred in about $20 \%$ of cases. ${ }^{21,22}$ Notably, the use of a corticosteroid upon PSA progression frequently led to subsequent secondary PSA declines, suggesting a reduction in the promiscuous AR activation by upstream steroidal precursors that are increased by feedback mechanisms. To conclusively evaluate the efficacy and safety of abiraterone, a pivotal multicenter placebocontrolled blinded randomized phase III trial (COU-AA-301) was conducted in men with docetaxel-pretreated ketoconazole-naïve metastatic CRPC. ${ }^{23}$ This trial randomized men $(2: 1)$ to receive either abiraterone $1000 \mathrm{mg}$ daily plus prednisone $10 \mathrm{mg}$ daily $(\mathrm{n}=797)$ or placebo plus prednisone $(\mathrm{n}=398)$. The trial met its primary endpoint, demonstrating a median overall survival of 14.8 months in the abiraterone arm and 10.9 months in the placebo arm (hazard ratio $0.65 ; P<0.0001$ ). In addition, when compared to placebo, abiraterone prolonged radiographic progression-free survival (5.6 vs 3.6 months; $P<0.0001$ ), improved time to PSA progression (10.2 vs 6.6 months; $P<0.0001$ ), and produced more PSA responses (38\% vs $10 \% ; P<0.0001)$. Notably, the overall survival duration seen here (14.8 months) is similar to that of cabazitaxel/prednisone (15.1 months) in this second-line 
population with similar baseline characteristics (Table 3), while the survival of men treated with prednisone alone was slightly inferior to that of mitoxantrone/prednisone in the TROPIC trial (10.9 vs 12.7 months). Based on the results of the COU-AA-301 trial, the FDA approved abiraterone with prednisone in April 2011 for use in patients with metastatic CRPC who have received prior docetaxel-based chemotherapy. A second randomized phase III trial (COU-AA-302) targeting men with docetaxel- and ketoconazole-naïve CRPC has completed accrual of over 1000 patients (Table 2). Given the comfort level and safety of using this and other hormonal agents in prostate cancer patients prior to chemotherapy, it is very likely that abiraterone will eventually be used clinically in both the pre-docetaxel and post-docetaxel settings. ${ }^{24}$

\section{Denosumab: an osteoclast-targeted therapy}

Interactions between tumor cells and the bone marrow microenvironment have been postulated as an important mechanism in the pathogenesis of bone metastasis. Tumorassociated cytokines have been shown to induce the expression of RANKL (receptor activator of nuclear factor- $\mathrm{\kappa B}$ ligand), which binds and activates RANK found on osteoclasts. ${ }^{25}$ Inhibition of RANKL has recently been the focus of much clinical research and represents an effective osteoclast-targeting strategy for patients with bone metastases.

Denosumab (Xgeva, Amgen) is a fully human monoclonal $\mathrm{IgG}_{2}$ antibody with a very high affinity for human RANKL. ${ }^{26}$ Denosumab has been examined in a variety of clinical settings including postmenopausal osteoporosis and other cancer subtypes demonstrating efficacy in bone-metastatic solid tumors predominantly. An early phase II study demonstrated that denosumab (120 mg subcutaneously every 4 weeks) was associated with a reduction of bone resorption compared to zoledronate ( $4 \mathrm{mg}$ intravenously every 4 weeks) as indicated by a lowering of urinary $\mathrm{N}$-telopeptide levels, and also resulted in fewer skeletalrelated events (SREs: pathologic fracture, radiation therapy, surgery to bone, spinal cord compression, or malignant hypercalcemia). ${ }^{27}$

Following from these encouraging results, a pivotal multi-center phase III double-blind randomized study was conducted comparing denosumab against zoledronate for the prevention of SREs in patients with bisphosphonate-naïve metastatic CRPC. In that trial of 1904 patients, compared to men receiving zoledronate $(n=951)$, men receiving denosumab $(\mathrm{n}=950)$ had an improved time to first SRE (20.7 vs 17.1 months; $P=0.008)$ and longer time to first-and-subsequent SRE (hazard ratio $0.82 ; P=0.004$ ). ${ }^{28}$ Notably, there was no difference in overall survival or progression-free survival between study arms. Based partially on the results of this study (and partially on two other large randomized studies in metastatic breast cancer and other solid metastatic tumors), the FDA approved denosumab in November 2010 for the prevention of SREs in patients with bone metastases from solid tumors. Common toxicities of denosumab include fatigue, nausea, hypophosphatemia, hypocalcemia (5\% grade 33 ), and osteonecrosis of the jaw (2\%), and prophylactic calcium and vitamin D supplementation is strongly encouraged. Therefore, denosumab is a reasonable alternative to zoledronate for the prevention of SREs in patients with metastatic CRPC, and also has the advantage that it does not require dose adjustment or monitoring for renal impairment. However, because of the risk of developing osteonecrosis of the jaw, a dental examination should be performed prior to starting this agent, and major dental procedures should be avoided while men are receiving this therapy.

\section{EMERGING AGENTS IN THE PIPELINE}

\section{Orteronel: a novel CYP17 inhibitor}

Orteronel (TAK-700) is a new oral, non-steroidal, selective CYP17 inhibitor that is more potent than abiraterone at suppressing extra-gonadal androgen biosynthesis without 
impairing cortisol production, ${ }^{29}$ providing a theoretical advantage of preventing ACTH feedback upregulation and avoiding complications related to secondary mineralocorticoid excess (Figure 2). In a phase I/II study using orteronel in patients with metastatic CRPC, $52 \%$ of men receiving daily doses of $\geq 600 \mathrm{mg}$ demonstrated $\geq 50 \%$ PSA reductions (and $29 \%$ of men showed $\$ 90 \%$ PSA declines). ${ }^{30}$ Importantly, the incidence of hypertension and hypokalemia in this trial was low, supporting the notion of preferential inhibition of C17,20lyase over 17a-hydroxylase in humans. Based on the initial promising activity, two multicenter randomized phase III trials of orteronel in combination with prednisone vs prednisone alone in metastatic CRPC have been launched both before and following docetaxel (Table 2).

\section{MDV3100: a novel androgen receptor antagonist}

A slightly different AR-directed approach has focused on the development of secondgeneration anti-androgens that have advantages over the established agents in this class (bicalutamide, nilutamide, flutamide). One such drug is MDV3100, a potent oral nonsteroidal AR antagonist (Figure 2). ${ }^{31}$ Importantly, MDV3100 remains a potent antagonist of the AR in the castration-resistant state, even in the setting of overexpressed or constitutively-activated AR. ${ }^{32}$ In addition, unlike other anti-androgens that may also function as partial AR agonists, MDV3100 does not exhibit any measurable agonistic activity, and is able to prevent AR nuclear translocation with resultant tumoricidal (not cytostatic) activity. ${ }^{33}$ Notably, recent studies have demonstrated the emergence of ligandindependent AR splice variants in CRPC, some of which may also be inhibited by MDV3100.

A phase I/II study of oral MDV3100 in men with chemotherapy-naïve ( $n=65)$ or taxanepretreated $(\mathrm{n}=75)$ metastatic CRPC has recently been published. ${ }^{34}$ In that trial, $250 \%$ PSA declines were seen in $62 \%$ and $51 \%$ of chemotherapy-naïve and taxane-pretreated patients respectively, objective tumor responses were observed in $36 \%$ and $12 \%$ of men respectively. Radiographic progression-free survival was 6.7 months in the docetaxel-pretreated patients, and >17 months in chemotherapy-naïve patients. Side effects of MDV3100 are generally mild, and include fatigue (27\%) and nausea (9\%). Rare seizures (3/140 patients) have also been reported, perhaps mediated by a direct effect of AR antagonism on central nervous system GABA-A receptors. ${ }^{35}$

A pivotal placebo-controlled double-blind phase III study (AFFIRM), randomizing 1170 patients with docetaxel-pretreated ketoconazole-naïve CRPC to MDV3100 $160 \mathrm{mg}$ daily $(\mathrm{n}=780)$ or placebo $(\mathrm{n}=390)$, has now completed accrual. A second randomized phase III trial (PREVAIL) investigating the same treatment arms in men with chemotherapy-naïve CRPC is currently underway (Table 2). One advantage of MDV3100 over agents such as abiraterone or orteronel is the lack of requirement for concurrent corticosteroid administration. However, the optimal sequencing of this agent, if approved, with immunotherapies and other emerging hormonal therapies will need to be defined through future clinical trials. Finally, newer AR antagonists (e.g. ARN-509 and others) have also entered early-phase clinical trials.

\section{Ipilimumab: immune checkpoint blockade}

Due to ongoing host immunological pressures on evolving tumors, cancers have developed mechanisms to escape immune surveillance, effectively inducing a state of immune tolerance. ${ }^{36}$ One way to inhibit immunological evasion by tumor cells is through blockade of the immune checkpoint molecule CTLA-4 (cytotoxic T lymphocyte-associated antigen-4), thus preventing the normal attenuation of antitumor T-cell responses. ${ }^{37} \mathrm{In}$ 
murine prostate cancer models, CTLA-4 inhibition has been shown to potentiate T-cell effects and induce tumor rejection.

Several clinical trials using the monoclonal anti-CTLA-4 antibody, ipilimumab, have been conducted in men with metastatic CRPC. These include phase I and II studies of ipilimumab monotherapy or in combination with radiation, ${ }^{38}$ as well as a phase I study combining ipilimumab with GM-CSF. ${ }^{39}$ Encouragingly, $250 \%$ PSA reductions have been observed in about $20 \%$ of patients, and radiological tumor responses were seen in about $5 \%$ of men, which is particularly noteworthy, given that PSA and tumor responses were rarely reported in the immunotherapy trials with sipuleucel-T or other therapeutic vaccines. Common side effects of ipilimumab include fatigue (42\%), nausea (35\%), pruritus (24\%), constipation (21\%), and rash (19\%). In addition, because CTLA-4 normally serves to attenuate autoimmunity, immunological toxicities resulting from an unchecked immune response may occur. Such immune-related adverse events include colitis (8\%), adrenal insufficiency (2\%), hepatitis (1\%), and even hypophysitis (1\%). ${ }^{40}$ Ipilimumab is now in placebo-controlled phase III testing in the post-docetaxel setting in men with CRPC following a palliative and perhaps immune-stimulatory dose of radiation to a metastatic site, with the intent to demonstrate a survival advantage over radiation alone. A second pre-docetaxel placebo controlled study is also underway (Table 2).

\section{CONCLUSIONS}

With more drugs at our fingertips for the treatment of metastatic CRPC than ever before, and an increasing number of novel therapeutic targets being discovered every day, we are still left with several challenges and unanswered questions. First, we must determine how these approved and experimental therapies should ideally be sequenced in individual patients with CRPC. For example, should sipuleucel-T routinely be given prior to chemotherapy or abiraterone with prednisone? Should abiraterone be reserved only for docetaxel-resistant patients? How should we treat cabazitaxel-refractory patients? Second, we will need to develop strategies to optimally combine these drugs in a rational manner, taking advantage of our understanding of negative feedback loops and alternative pathway activation to overcome resistance to monotherapies. Ultimately, only prospective trials incorporating biomarker-driven hypotheses will be able to address these key clinical questions. Thus, the collection of tumor specimens or correlative samples may be essential in identifying novel targets or developing enrichment strategies for future study of these agents. Third, we must design smarter trials with the goal of quickly yet reliably identifying agents that do not hold promise, while enabling those that do to move swiftly to registrational studies. For example, in the clinical development of MDV3100 and cabazitaxel, pivotal phase III trials were designed directly following the initial phase I/II studies that demonstrated significant drug activity in men with CRPC. Finally, we must select our patients more carefully based on clinical or molecular characteristics, in order to identify the subset most likely to benefit from a particular therapy. For example, in men with significant pain, perhaps sipuleucel-T is not appropriate systemic therapy given the prolonged onset of action and lack of palliative benefits; additionally, immune-based biomarkers may shed light on which men may obtain a greater degree of benefit from immunotherapies.

In conclusion, cabazitaxel was the first agent to be approved by the FDA for men with metastatic CRPC who have progressed after docetaxel chemotherapy, and abiraterone acetate was the second FDA-approved drug in this same patient population. In addition, sipuleucel-T has been FDA approved for patients with asymptomatic or minimally symptomatic metastatic CRPC, and may be best utilized in men without visceral metastases. In addition, denosumab gained FDA approval for the prophylaxis of skeletal-related events 
in men with castration-resistant bone metastases, and may have some advantages over zoledronate. In addition, palliative radiation or radiopharmaceuticals (e.g. samarium, strontium, or investigational radium) may also play a significant role in the management of men with symptomatic disease, both before or after systemic therapies. Several additional active agents are currently in phase III development, and some of these therapies are also likely to further expand our therapeutic arsenal for men with metastatic CRPC in the near future.

\section{Supplementary Material}

Refer to Web version on PubMed Central for supplementary material.

\section{References}

1. Jemal A, Siegel R, Xu J, Ward E. Cancer statistics, 2010. CA Cancer J Clin. 2010; 60:277-300. [PubMed: 20610543]

2. Tannock IF, de Wit R, Berry WR, Horti J, Pluzanska A, Chi KN, et al. Docetaxel plus prednisone or mitoxantrone plus prednisone for advanced prostate cancer. N Engl J Med. 2004; 351:1502-1512. [PubMed: 15470213]

3. Petrylak DP, Tangen CM, Hussain MH, Lara PN Jr, Jones JA, Taplin ME, et al. Docetaxel and estramustine compared with mitoxantrone and prednisone for advanced refractory prostate cancer. N Engl J Med. 2004; 351:1513-1520. [PubMed: 15470214]

4. Tannock IF, Osoba D, Stockler MR, Ernst DS, Neville AJ, Moore MJ, et al. Chemotherapy with mitoxantrone plus prednisone or prednisone alone for symptomatic hormone-resistant prostate cancer: a Canadian randomized trial with palliative end points. J Clin Oncol. 1996; 14:1756-1764. [PubMed: 8656243]

5. Antonarakis ES, Drake CG. Current status of immunological therapies for prostate cancer. Curr Opin Urol. 2010; 20:241-246. [PubMed: 20179598]

6. Small EJ, Fratesi P, Reese DM, Strang G, Laus R, Peshwa MV, et al. Immunotherapy of hormonerefractory prostate cancer with antigen-loaded dendritic cells. J Clin Oncol. 2000; 18:3894-3903. [PubMed: 11099318]

7. Small EJ, Schellhammer PF, Higano CS, Redfern CH, Nemunaitis JJ, Valone FH, et al. Placebocontrolled phase III trial of immunologic therapy with sipuleucel-T (APC8015) in patients with metastatic, asymptomatic hormone refractory prostate cancer. J Clin Oncol. 2006; 24:3089-3094. [PubMed: 16809734]

8. Higano CS, Schellhammer PF, Small EJ, Burch PA, Nemunaitis J, Yuh L, et al. Integrated data from 2 randomized, double-blind, placebo-controlled, phase 3 trials of active cellular immunotherapy with sipuleucel-T in advanced prostate cancer. Cancer. 2009; 115:3670-3679. [PubMed: 19536890]

9. Kantoff PW, Higano CS, Shore ND, Berger ER, Small EJ, Penson DF, et al. Sipuleucel-T immunotherapy for castration-resistant prostate cancer. N Engl J Med. 2010; 363:411-422. [PubMed: 20818862]

10. Kantoff PW, Schuetz TJ, Blumenstein BA, Glode LM, Bilhartz DL, Wyand M, et al. Overall survival analysis of a phase II randomized controlled trial of a poxviral-based PSA-targeted immunotherapy in metastatic castration-resistant prostate cancer. J Clin Oncol. 2010; 28:1099_ 1105. [PubMed: 20100959]

11. Hoos A, Eggermont AM, Janetzki S, Hodi FS, Ibrahim R, Anderson A, et al. Improved endpoints for cancer immunotherapy trials. J Natl Cancer Inst. 2010; 102:1388-1397. [PubMed: 20826737]

12. Paller CJ, Antonarakis ES. Cabazitaxel: a novel second-line treatment for metastatic castrationresistant prostate cancer. Drug Des Devel Ther. 2011; 5:117-124.

13. Attard G, Greystoke A, Kaye S, de Bono J. Update on tubulin-binding agents. Pathol Biol. 2006; 54:72-84. [PubMed: 16545633]

14. Mita AC, Denis LJ, Rowinsky EK, de Bono JS, Goetz AD, Ochoa L, et al. Phase I and pharmacokinetic study of XRP6258 (RPR 116258A), a novel taxane, administered as a 1-hour 
infusion every 3 weeks in patients with advanced solid tumors. Clin Cancer Res. 2009; 15:723730. [PubMed: 19147780]

15. de Bono JS, Oudard S, Ozguroglu M, Hansen S, Machiels JP, Kocak I, et al. Prednisone plus cabazitaxel or mitoxantrone for metastatic castration-resistant prostate cancer progressing after docetaxel treatment: a randomised open-label trial. Lancet. 2010; 376:1147-1154. [PubMed: 20888992]

16. Mohler J, Bahnson RR, Boston B, Busby JE, D'Amico A, Eastham JA, et al. NCCN clinical practice guidelines in oncology: prostate cancer. J Natl Compr Canc Netw. 2010; 8:162-200. [PubMed: 20141676]

17. O'Donnell A, Judson I, Dowsett M, Raynaud F, Dearnaley D, Mason M, et al. Hormonal impact of the 17a-hydroxylase/C(17,20)-lyase inhibitor abiraterone acetate $(\mathrm{CB} 7630)$ in patients with prostate cancer. Br J Cancer. 2004; 90:2317-2325. [PubMed: 15150570]

18. Attard G, Reid AH, Yap TA, Raynaud F, Dowsett M, Settatree S, et al. Phase I clinical trial of a selective inhibitor of CYP17, abiraterone acetate, confirms that castration-resistant prostate cancer commonly remains hormone driven. J Clin Oncol. 2008; 26:4563-4571. [PubMed: 18645193]

19. Attard G, Reid AH, A'Hern R, Parker C, Oommen NB, Folkerd E, et al. Selective inhibition of CYP17 with abiraterone acetate is highly active in the treatment of castration-resistant prostate cancer. J Clin Oncol. 2009; 27:3742-3748. [PubMed: 19470933]

20. Ryan CJ, Smith MR, Fong L, Rosenberg JE, Kantoff P, Raynaud F, et al. Phase I clinical trial of the CYP17 inhibitor abiraterone acetate demonstrating clinical activity in patients with castrationresistant prostate cancer who received prior ketoconazole therapy. J Clin Oncol. 2010; 28:14811488. [PubMed: 20159824]

21. Reid AH, Attard G, Danila DC, Oommen NB, Olmos D, Fong PC, et al. Significant and sustained antitumor activity in post-docetaxel, castration-resistant prostate cancer with the CYP17 inhibitor abiraterone acetate. J Clin Oncol. 2010; 28:1489-1495. [PubMed: 20159823]

22. Danila DC, Morris MJ, de Bono JS, Ryan CJ, Denmeade SR, Smith MR, et al. Phase II multicenter study of abiraterone acetate plus prednisone therapy in patients with docetaxel-treated castrationresistant prostate cancer. J Clin Oncol. 2010; 28:1496-1501. [PubMed: 20159814]

23. de Bono JS, Logothetis CJ, Molina A, Fizazi K, North S, Chu L, et al. Abiraterone and increased survival in metastatic prostate cancer. N Engl J Med. 2011; 364:1995-2005. [PubMed: 21612468]

24. Antonarakis ES, Eisenberger MA. Expanding treatment options for metastatic prostate cancer. N Engl J Med. 2011; 364:2055-2058. [PubMed: 21612475]

25. Brown JM, Corey E, Lee ZD, et al. Osteoprotegerin and RANK ligand expression in prostate cancer. Urology. 2001; 57:611-616. [PubMed: 11306358]

26. Vallet S, Smith MR, Raje N. Novel bone-targeted strategies in oncology. Clin Cancer Res. 2010; 16:4084-4093. [PubMed: 20643782]

27. Fizazi K, Lipton A, Mariette X, Body JJ, Rahim Y, Gralow JR, et al. Randomized phase II trial of denosumab in patients with bone metastases from prostate cancer, breast cancer, or other neoplasms after intravenous bisphosphonates. J Clin Oncol. 2009; 27:1564-1571. [PubMed: 19237632]

28. Fizazi K, Carducci M, Smith M, Damiao R, Brown J, Karsh L, et al. Denosumab versus zoledronic acid for treatment of bone metastases in men with castration-resistant prostate cancer: a randomized double-blind study. Lancet. 2011; 377:813-822. [PubMed: 21353695]

29. Vasaitis TS, Bruno RD, Njar VC. CYP17 inhibitors for prostate cancer therapy. J Steroid Biochem Mol Biol. 2010 epub ahead of print.

30. Dreicer R, Agus DB, MacVicar GR, Wang J, MacLean D, Stadler WM. Safety, pharmacokinetics, and efficacy of TAK-700 in metastatic castration-resistant prostate cancer: a phase I/II, open-label study. J Clin Oncol. 2010; 28(Suppl) abstract 3084.

31. Chen Y, Clegg NJ, Scher HI. Anti-androgens and androgen-depleting therapies in prostate cancer: new agents for an established target. Lancet Oncol. 2009; 10:981-991. [PubMed: 19796750]

32. Watson PA, Chen YF, Balbas MD, Wongvipat J, Socci ND, Viale A, et al. Constitutively active androgen receptor splice variants expressed in castration-resistant prostate cancer require fulllength androgen receptor. Proc Natl Acad Sci USA. 2010; 107:16759-16765. [PubMed: 20823238] 
33. Tran C, Ouk S, Clegg NJ, Chen Y, Watson PA, Arora V, et al. Development of a secondgeneration antiandrogen for treatment of advanced prostate cancer. Science. 2009; 324:787-790. [PubMed: 19359544]

34. Scher HI, Beer TM, Higano CS, Anand A, Taplin ME, Efstathiou E, et al. Antitumour activity of MDV3100 in castration-resistant prostate cancer: a phase 1-2 study. Lancet. 2010; 375:14371446. [PubMed: 20398925]

35. Foster WR, Car BD, Shi H, Levesque PC, Obermeier MT, Gan J, et al. Drug safety is a barrier to the discovery and development of new androgen receptor antagonists. Prostate. 2011; 71:480-488. [PubMed: 20878947]

36. Drake CG, Jaffee E, Pardoll DM. Mechanisms of immune evasion by tumors. Adv Immunol. 2006; 90:51-81. [PubMed: 16730261]

37. Hodi FS. Cytotoxic T-lymphocyte-associated antigen-4. Clin Cancer Res. 2007; 13:5238-5242. [PubMed: 17875750]

38. Small EJ, Tchekmedyian NS, Rini BI, Fong L, Lowy I, Allison JP. A pilot trial of CTLA-4 blockade with human anti-CTLA-4 in patients with hormone-refractory prostate cancer. Clin Cancer Res. 2007; 13:1810-1815. [PubMed: 17363537]

39. Fong L, Kwek SS, O’Brien S, Kavanagh B, McNeel DG, Weinberg V, et al. Potentiating endogenous antitumor immunity to prostate cancer through combination immunotherapy with CTLA4 blockade and GM-CSF. Cancer Res. 2009; 69:609-615. [PubMed: 19147575]

40. Dillard T, Yedinak CG, Alumkal J, Fleseriu M. Anti-CTLA-4 antibody therapy associated autoimmune hypophysitis: serious immune related adverse events across a spectrum of cancer subtypes. Pituitary. 2010; 13:29-38. [PubMed: 19639414] 


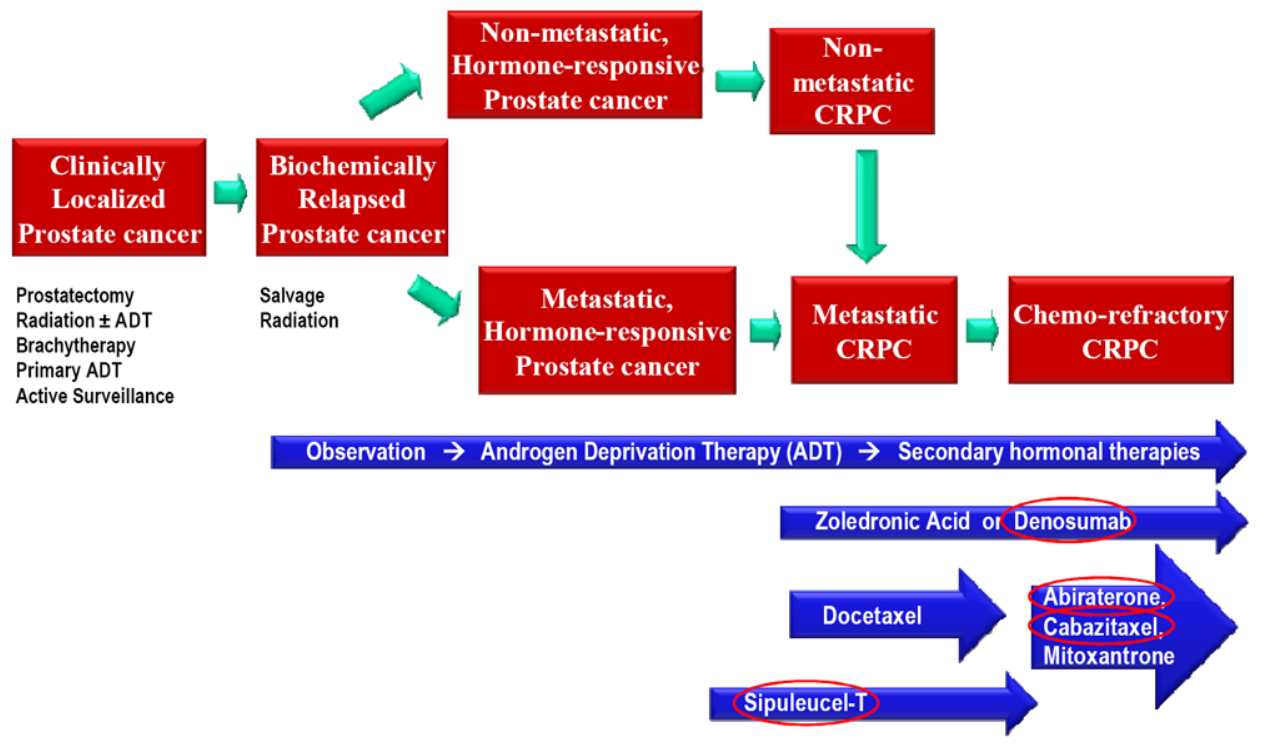

Figure 1. The therapeutic landscape for prostate cancer in 2011

Abbreviations: ADT, androgen deprivation therapy; CRPC, castration-resistant prostate cancer 


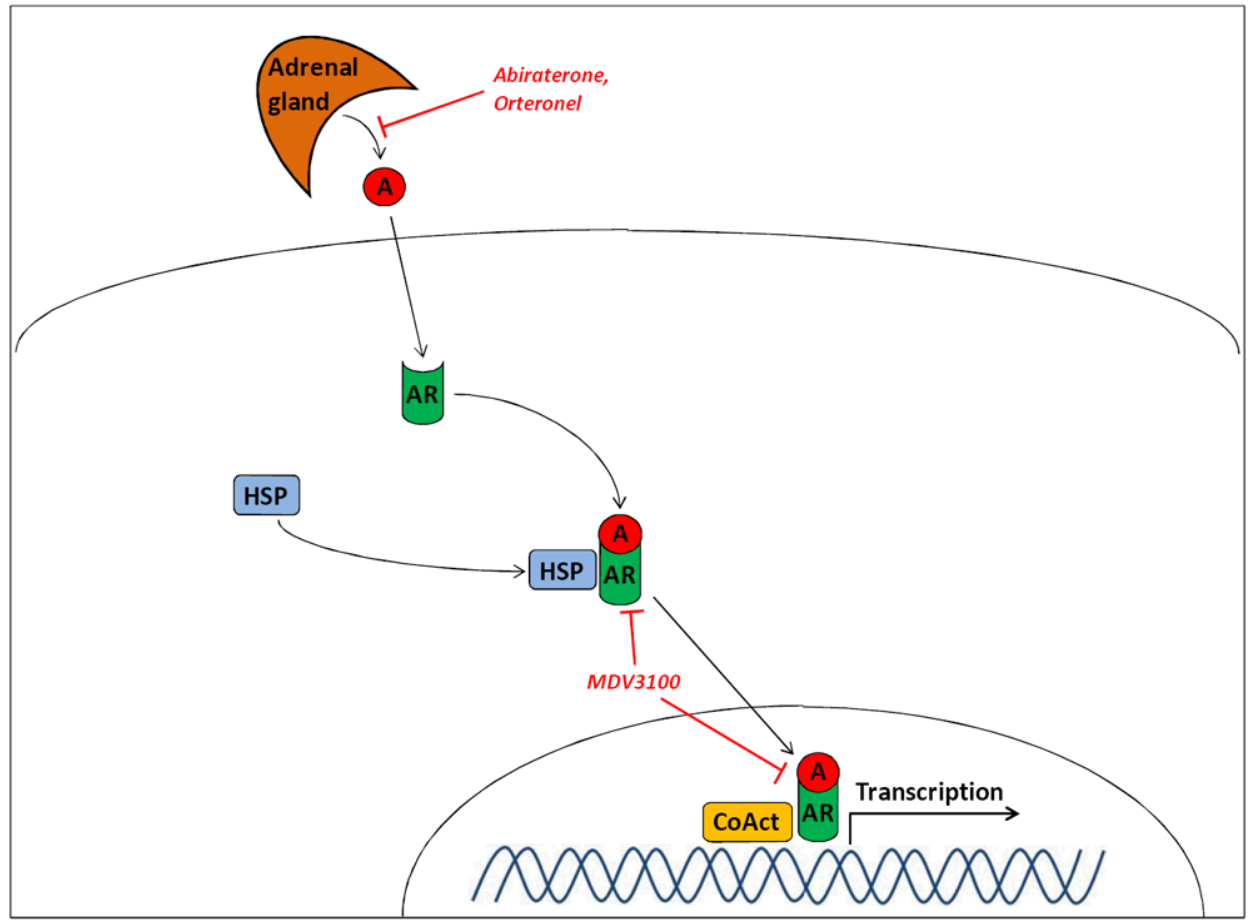

Figure 2. The androgen signaling axis in CRPC

Abbreviations: CRPC, castration-resistant prostate cancer; AR, androgen receptor; A; androgen; HSP, heat shock protein; CoAct; transcriptional coactivators. 
Table 1

Mechanisms of castration resistance in prostate cancer.

\begin{tabular}{|c|c|}
\hline Androgen receptor $(\boldsymbol{A R})$-dependent mechanisms \\
\hline Persistent AR signaling \\
0 & Amplification of the $A R$ gene \\
& Increased expression of the AR protein \\
0 & Greater stability and nuclear localization of the AR protein \\
0 & Genetic mutations in the $A R$ gene \\
0 & Promiscuous AR activation (e.g. by estrogens, progestins, tyrosine kinases) \\
0 & Ligand-independent (constitutive) activation of the AR protein \\
0 & Active $A R$ mRNA splice variants \\
0 & AR-dependent fusion proteins (e.g. TMPRSS2-ERG)
\end{tabular}

- Ectopic androgen synthesis
O Androgen synthesis by adrenal glands
Intratumoral androgen synthesis
Increased conversion of extra-gonadal androgens to testosterone

- Modulation of AR coregulators
O Overexpression of steroid receptor coactivators (e.g. p160, NCOA2)
○ Downregulation of steroid receptor corepressors (e.g. $\beta$-arrestin 2)
O Facilitation of AR-mediated transcription

Androgen receptor (AR)-independent mechanisms

- $\quad$ Activation of the PI3K/Akt/mTOR pathway

- Activation of the Ras/Raf/MEK/ERK pathway

- Proliferative signals (e.g. Myc, tubulin signaling)

- Overexpression of anti-apoptotic proteins (e.g. Bcl-2, Bcl-XL, clusterin, survivin)

- $\quad$ Survival signals (e.g. JNK, VEGF, MET)

- Activation of other pathways (e.g. TGF- $\beta \mathrm{R}, \mathrm{Wnt} / \beta$-catenin, Src kinase, IL-6R)

- Bone microenvironment (e.g. endothelin, RANK ligand)

- Stem cell factors (e.g. Hedgehog) and epithelial-mesenchymal transition programs

- $\quad$ DNA repair programs

- Immunological escape/tolerance 


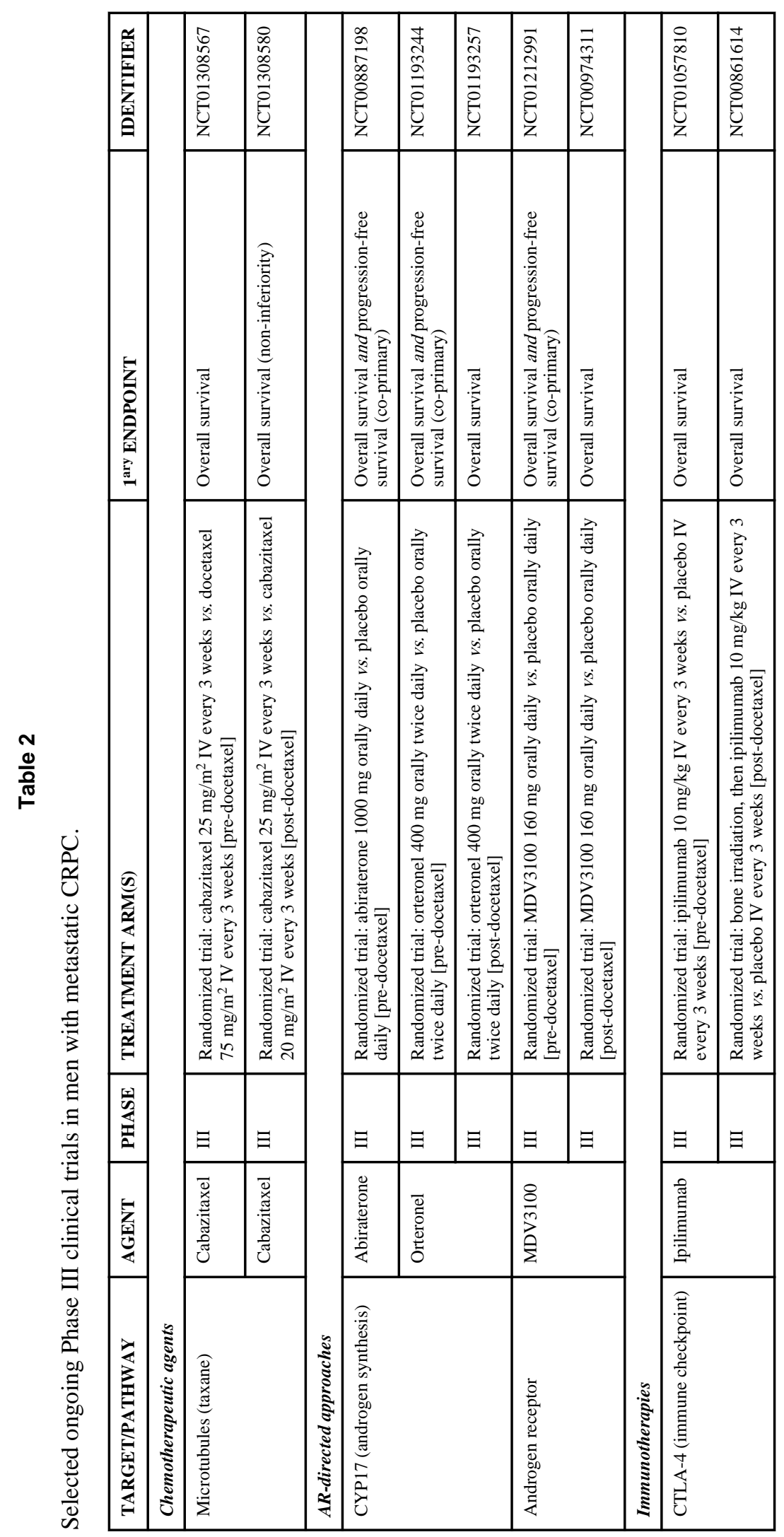

Eur Urol Rev. Author manuscript; available in PMC 2013 June 18. 
Table 3

Comparison of the two pivotal second-line trials for men with metastatic CRPC: COU-AA-301 versus TROPIC.

\begin{tabular}{|l|l|l|}
\hline & Cabazitaxel/Prednisone (TROPIC) & Abiraterone/Prednisone (COU-AA-301) \\
\hline Median baseline PSA & $144 \mathrm{ng} / \mathrm{mL}$ & $129 \mathrm{ng} / \mathrm{mL}$ \\
\hline Pain at baseline & $46 \%$ & $44 \%$ \\
\hline Presence of visceral disease & $25 \%$ & $29 \%$ \\
\hline Two (or more) prior chemotherapies & $31 \%$ & $30 \%$ \\
\hline Median overall survival & 15.1 months & 14.8 months \\
\hline Median time to tumor progression & 8.8 months & 5.6 months \\
\hline Median time to PSA progression & 6.4 months & 10.2 months \\
\hline PSA response rate ( $250 \%$ PSA decline) & $39 \%$ & $29 \%$ \\
\hline Objective response rate & $14 \%$ & $14 \%$ \\
\hline Pain response & $9 \%$ & $44 \%$ \\
\hline
\end{tabular}

